DOI: http://dx.doi.org/10.22484/2177-5788.2016v42n1p213-229

\title{
Dois projetos de tradução da Antipoesia no Brasil
}

\author{
Mary Anne Warken S. Sobottka
}

Resumo: O objetivo deste artigo é analisar duas seleções de antipoemas do chileno Nicanor Parra (1914-), traduzidos para o português por Juvenal Neto e Carlos Nejar, publicados no Brasil respectivamente em 1981 e 2009. Essas traduções serão comentadas a partir das considerações de Antoine Berman sobre a crítica da tradução.

Palavras-chave: Antipoesia. Nicanor Parra. Antoine Berman. Poesia. Tradução.

\section{Antipoetry in Brazil: Two translation projects}

Abstract: This paper aims at analyzing two selected antipoems by the chilean Nicanor Parra, respectively translated to the Brazilian Portuguese by Juvenal Neto and Carlos Nejar, and subsequently published in 1981 and 2009. These translations will be commented based on Antoine Berman works on translation criticism.

Keywords: Antipoetry. Nicanor Parra. Antoine Berman. Poetry. Translation. 
SOBOTTKA, Mary Anne Warken S. Dois projetos de tradução da antipoesia no Brasil.

\section{Introdução}

O presente artigo tem por objetivo analisar duas traduções de antipoemas feitas no Brasil, sob a luz dos pensamentos de Antoine Berman (1942-1991). De forma conjunta discutiremos os principais aspectos da antipoesia.

Nicanor Parra nasceu em Biobío, uma região ao sul do Chile, em 1914, no dia 5 de setembro, e em 2015 festejou seu aniversário número 101. Suas obras contemplam publicações desde 1938 até o ano de 2016. Inaugurou oficialmente a antipoesia em 1954 com a publicação do seu livro Poemas e Antipoemas. Roberto Fernández Retamar, em sua conferência Antipoesía y poesía conversacional en Hispanoamérica, em 1968, confere a Nicanor Parra a paternidade da antipoesia atual.

Conforme afirma o crítico Niall Binns, ${ }^{1 "}$ estamos diante de um caso único: um poeta com uma denominação de origem só para ele. "[...] Nicanor Parra, e nada mais que Nicanor Parra, é o antipoeta" (BINNS, 2011, p. 132). Parra é poeta, antipoeta, físico, matemático, e também tradutor, em 2004 publicou a tradução de o Rey Lear de William Shakespeare, com o título Lear Rey \& Mendigo. Os antipoemas de Parra foram traduzidos ao inglês nos anos sessenta por Jorge Elliot, Antipoems (1962). Também foram traduzidos pelo poeta da geração beat, Allen Ginsberg, por William Carlos Williams, por Lawrence Ferlinghetti, editor, poeta beat e pintor, e por Thomas Merton.

A antipoesia de Parra em 1954 marcou distância da poesia de Pablo Neruda, Vicente Huidobro e Gabriela Mistral, poetas consagrados na literatura latino-americana; porém, o crítico chileno Federico Schopf nos lembra: "não se deve perder de vista que a obra de Parra começou por não ser antipoesia. Os antipoemas são o resultado - um dos resultados possíveis de antagonismos diversos"2 (SCHOPF, 1984, s.p.). Uma das questões mais importantes ao

\footnotetext{
${ }^{1}$ Estamos ante un caso unico: un poeta con una denominación de origen solo para él. [...]. Nicanor Parra, y nada más que Nicanor Parra, es el antipoeta". (BINNS, 2011, p. 132)

2 "Pero no debe perderse de vista que la obra de Parra ha comenzado por no ser antipoesía. Los antipoemas son el resultado -uno de los resultados posibles- de antagonismos diversos. Los antipoemas no se oponen totalmente al tipo de poesía inmediatamente anterior -generado por las vanguardias-, del cual prolonga incluso rasgos constitutivos, sino a un agregado de rasgos pertenecientes a varios tipos de poesía, distribuidos diacrónicamente a partir del modernismo." (minha tradução, SCHOPF, 1984) *Todas as citações foram traduzidas por mim do espanhol para o português.
} 
analisar a escritura poética de Parra é considerar a definição de antipoesia e, para tentar esclarecer essa interrogante, é válido lembrar a entrevista feita pelo crítico chileno Manuel Jofré ao antipoeta. Nesta entrevista, Parra se refere à possível definição de antipoético. Para o antipoeta, esta pergunta comporta várias possibilidades de interpretação e uma série de respostas, mas entre elas está a de que a antipoesia é a poesia do sentido comum, que é o menos comum dos sentidos. Da mesma forma, lembra que, uma vez que está relacionada ao sentido comum, a antipoesia deve estar concebida em uma linguagem igualmente comum, sem retórica ou jargão poético. Afirma ele: "Melhor. Teríamos que ver como nos comunicamos. Qual é a forma correta ou mais satisfatória por meio das palavras, porque os métodos de comunicação vão envelhecendo" (JOFRE, 2000) ${ }^{3}$.

\section{Justificativa}

A comemoração do centenário de Parra em 2014 foi repleta de eventos e publicações no Chile, em outros países e, também no Brasil. A Universidade de São Paulo, em outubro de 2015, no evento Centenarios al Sur: Paz, Parra, Cortázar, Bioy, contou com a presença de um dos críticos da antipoesia, Federico Schopf, da Universidade do Chile.

Esse artigo faz uma retrospectiva e traz dois projetos de tradução que foram publicados anos antes de Parra ter recebido o prêmio Cervantes e de ser um poeta centenário. Uma das publicações aqui estudadas é de Juvenal Neto, poeta e jornalista responsável pela revista Pirâmide, onde, sob o título: Quatro Poetas Latino-Americanos por Juvenal Neto, publicou a tradução de alguns antipoemas de Nicanor Parra. A revista teve um único número, ano 1981, publicação da USP através do Centro Acadêmico Oswald de Andrade de Estudos Literários e Linguística (CAELL). O outro projeto é publicado pela Academia Brasileira de Letras, em 2009, e a tradução dos antipoemas, assim como o paratexto introdutório, é de responsabilidade do Poeta Carlos Néjar, que também é um dos membros da Academia.

\footnotetext{
3 "Mejor. Habría que ver cómo nos comunicamos. Cúal es la forma correcta o más satisfactoria mediante las palabras, porque los métodos de comunicación se van envejeciendo" (JOFRE, 2000).
} 


\section{A tradução é sempre introdução}

Em A Tradução e a Letra (1985), Berman, ao referir-se sobre o propósito da tradução, apresenta a seguinte interrogante: “A tradução é sempre introdução?” E no que concerne à recepção afirma:

[...] popularizar o original não significa vulgarizá-lo. Emendar as estranhezas de uma obra para facilitar sua leitura acaba por desfigurá-la, e portanto, enganar o leitor a quem se pretende servir. Precisa-se, antes, como no caso da ciência, de uma educação à estranheza. (BERMAN, 1985 [2007], p. 91)

Sabemos que a antipoesia ainda é pouco estudada no Brasil, devido a isso, é importante que para analisar os antipoemas traduzidos aqui, recorramos também a crítica literária e suas considerações ao respeito da construção poética contida na escritura de Nicanor Parra. A seguir enfatizamos alguns elementos importantes na antipoesia, e logo comentaremos as traduções realizadas no Brasil pelos tradutores Carlos Nejar e por Juvenal Neto, tendo como base as considerações de Antoine Berman sobre a tradução.

O crítico chileno Leonidas Morales, em seu artigo: Nicanor Parra: El Proyecto Antipoético (2012), aponta para um projeto de escritura antipoética e descreve as etapas deste projeto que abarca publicações de poemas, antipoemas e poesia visual. Devemos enfatizar aqui que a primeira publicação de Parra foi em 1938; e agora em 2015 temos o anúncio do lançamento do livro Antiprosa, pela editora da Universidad Diego Portales. Na apresentação do livro, Carlos Peña adverte que a antiprosa antecedeu a antipoesia (PEÑA, 2015, s.p). A antipoesia ultrapassou as barreiras do tempo, da ditadura e da censura do governo do general Pinochet no Chile. Na antipoesia, o humor, o sarcasmo e a ironia se complementam. A voz poética se contradiz, e se permite comunicar com seu leitor através de várias vozes, de vários personagens. Esses elementos podem ser ilustrados nos dois antipoemas abaixo: 
SOBOTTKA, Mary Anne Warken S. Dois projetos de tradução da antipoesia no Brasil.

\section{La Montaña Rusa}

Durante medio siglo

La poesía fue

El paraíso del tonto solemne

Hasta que vine yo

$Y$ me instalé

Con mi montaña rusa

(PARRA, 1962 [2006], p. 86)

\section{La poesía terminó conmigo}

Yo no digo que ponga fin a nada No me hago ilusiones al respecto Yo querría seguir poetizando Pero se terminó la inspiración La poesía se ha portado bien Yo me he portado horriblemente mal Qué gano con decir Yo me he portado bien La poesia se ha portado mal Cuando saben que yo soy el culpable ¡Está bien que me pase por imbécil! La poesía se ha portado bien Yo me he portado horriblemente mal La poesía terminó conmigo.

(PARRA, 1962 [2006], p. 108)

No antipoema Montaña Rusa, a voz poética afirma sua posição e desterritorializa a poesia, no antipoético "la poesía fue el paraíso del tonto solemne". Se fazemos a comparação com o discurso de outro antipoema "La poesía terminó conmigo", temos uma voz poética que joga com o leitor, o eu lírico se coloca como um personagem que se comportou mal, que está sem inspiração, uma posição contrária ao alter ego dos versos de Montaña Rusa.

Binss (2011, p. 138) destaca que:

[...] ler a poesia de Parra como antipoesia significa estar condenado a lê-la em função da ruptura. É uma boa forma historicista de ler a Parra, e é o que constantemente fazem os críticos. Mas, mais produtivo, mais interessante, mais vital, seria ler a obra de Parra como poesia, ou bem, como uma expressão poética - eu diria, uma das expressões 
poéticas mais intensas - da nossa época conturbada, que se desenvolve em constante diálogo - e não só em rupturas - com os demais. ${ }^{4}$

Todos estes elementos devem ser considerados no momento de analisar e realizar a tradução da antipoesia. A ironia é um elemento de destaque, e Salvador Galán Moreu, em Antipoesía e ironía: una introducción (2008), aponta como um exemplo de presença da ironia na antipoesia o seguinte antipoema:

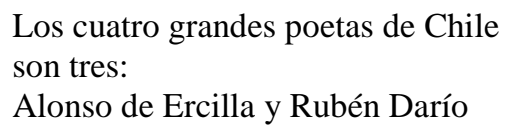

(PARRA apud BOLAÑO, 2001)

Nesse antipoema, Parra replica os versos do prefácio de Altazor (Huidobro, 1931): "os quatro pontos cardinais são três: norte e sul", e instala o tom irônico ao citar Ercilla (15331594), poeta espanhol, e Darío (1867-1916), poeta nicaraguense. Deixa-nos a reflexão de que as constantes citações de outros autores nos versos antipoéticos, mais que distanciar-se, estabelecem um diálogo constante com importantes autores e momentos da literatura. Ruben Darío esteve no Chile em 1886, levando com ele a concepção de uma nova corrente para a literatura, o modernismo. A presença de Darío marcou o ambiente literário chileno, assim como sua experiência no Chile serviu de inspiração para suas obras, publicou dois livros: Emelina (1887) e Abrojos (1887). Este período pode ser entendido sob a perspectiva de Angel Rama, em La Ciudad Modernizada.

Rama (1998) enfatiza o papel fundamental da cidade letrada, o período marcado pelo modernismo se conforma através das letras desde a cidade real. Os aspectos culturais, entre eles, a oralidade, tão importante para a antipoesia, são elementos considerados por Rama para suas reflexões desse período histórico. Temos nesses três versos acima enlaces com questões importantes na literatura latino-americana. Parra replica versos de Huidobro, poeta que inaugurou a vanguarda, assim como aponta a influência de Darío, um dos ícones do

\footnotetext{
4 "leer la poesía de Parra como antipoesía significa estar condenado a leerla en función de la ruptura. Es una buena forma historicista de leer a Parra, y en ella nos caemos constantemente los críticos. Pero más productivo, más interesante, más vital, es leer la obra de Parra como poesía, o bien, como una expresión poética -yo diría, una de las expresiones poéticas más intensas- de nuestra época convulsa, que se desarrolla en constante diálogo -y no sólo ruptura- con los demás" (tradução nossa, BINNS, 2011, p. 138)
} 
modernismo. Instala-se, assim, uma leitura que permite ao leitor descobrir ou destapar os versos antipoéticos como bonecas russas, um tema contido em outro. A intertextualidade e reflexão poética nos versos colocam em questão a conformação de literatura, neste caso a chilena, resgatada ao mencionar Ercilla, espanhol que viveu pouco tempo no Chile, mas que foi o fundador da literatura chilena com a obra La Araucana $(1569 ; 1578 ; 1589)$.

Este procedimento de Parra pode ser vinculado à tradução hipertextual, que "remete a qualquer texto gerado por imitação, paródia, pastiche ou adaptação”. Podemos enfatizar a afirmação de que "do ponto de vista estrutural as relações hipertextuais estão muito próximas da tradução" (BERMAN, 1985 [2007], p. 47). Cabe ao tradutor estabelecer seu projeto, sempre considerando que a tradução da antipoesia requer mais que um domínio linguístico e exige uma apropriação e conhecimento do que é a antipoesia. Ainda que na sua primeira publicação, Cancionero sin nombre, de 1937, Parra remete a estética estabelecida por Petrarca, ao mesmo tempo segue o modelo poético de Garcia Lorca. É em 1954 que inaugura-se a antipoesia, a intertextualidade vai incorporar a ironia, a crítica e o humor negro. $\mathrm{O}$ antipoeta se utiliza do conhecimento erudito para jogar com o leitor e estabelecer uma nova construção poética. A seguir analisaremos e comentaremos dois projetos de tradução publicados no Brasil.

\section{Tradução de Juvenal Neto}

Juvenal Neto traduziu em 1981, pela Universidade de São Paulo, Vicente Huidobro, Nicanor Parra, Lezama Lima e Octavio Paz. O tradutor selecionou oito antipoemas, todos publicados somente em português. A seleção feita por Neto difere totalmente da de Nejar e não temos coincidência de antipoemas nessas publicações. São dois projetos diferentes, sendo que cronologicamente a publicação de Juvenal Neto antecede a de Carlos Nejar. Nesta análise destacamos o poema visual do livro Canciones Rusas, que aqui colocamos no seu idioma espanhol para melhor analisar: 
SOBOTTKA, Mary Anne Warken S. Dois projetos de tradução da antipoesia no Brasil.

niom.

Nicanor Parra

SOLO

Poco

a poco

poco

fui

quedando

solo

Imperceptiblemente:

Poco

a

poco.

Triste es la situación

Del que gozó de buena compañia

Y la perdió por un motivo u otro.

No me quejo de nada: tuve todo

Pero

$\sin$

darme

cuenta

Como árbol que pierde una a una sus hojas

Fuime

quedando

solo

poco

a

poco.

(PARRA, 2006, p. 159)
Tradução de Juvenal Neto:

SÓ

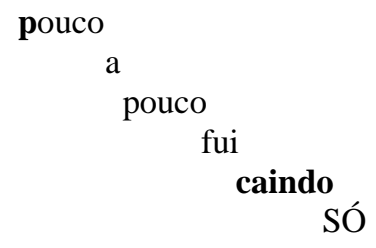

pouco

a

pouco

fui

caindo

SÓ

imperceptivelmente

pouco

a

pouco

triste situação:

gozar de boa companhia

e perdê-la por qualquer motivo

não me queixo de nada: tive tudo

mas

sem

perceber...

como a árvore que perde uma a uma suas folhas fui

caindo

Só

pouco

a

pouco

(Tradução de Juvenal Neto, 1981) 
Nos versos a seguir o tradutor opta por eliminar o pronome me, também troca o verbo quedar em português (ficar) por "cair". Ocorre modificação estética, já que altera a primeira letra do último verso, que passa a ser maiúscula na versão em português. Visualmente este último verso se sobressai e passa a ter só uma sílaba, é acentuado e sua primeira letra está em maiúscula.

me

fui

quedando fui caindo

A letra $\mathrm{P}$, que aparece no texto fonte em maiúscula no primeiro verso, está em minúscula na tradução. A colocação dos versos, em sua estrutura aparece modificada, em comparação com a versão no espanhol. Nos versos abaixo observamos tanto uma mudança visual e estética como na sua construção poética:

$\sin$

darme cuenta sem

perceber...

Temos na versão em espanhol três versos, já na versão em português temos somente dois versos e a inclusão das reticências. Podemos observar a busca do tradutor pelo sentido, ao traduzir: sin darme cuenta por sem perceber. Nessa opção a estrutura estética do antipoema difere bastante da sua versão em espanhol. Uma outra alternativa seria: "sem me dar conta" o que manteria a quantidade de sílabas e a sonoridade do verso.

Cabe observar que estamos diante da antipoesia, que não apresenta nestes versos a rima, mas que, sim, como a prosa, tem na escolha de suas palavras um determinado ritmo. A linguagem antipoética se propõe a estar próxima da oralidade. Berman aponta que a destruição do ritmo também pode ser alcançada ao momento de traduzir com a pontuação, ao pontuar onde 
antes não havia pontuação o tradutor está interferindo no ritmo, deve-se analisar e sopesar a necessidade dessas modificações (BERMAN, 2007, p. 78).

\section{Tradução de Carlos Nejar}

Ficcionista, poeta e tradutor, Luís Carlos Verzono Nejar é membro da Academia Brasileira de Letras desde maio de 1989, e publicou em 2009 a tradução de uma seleção de antipoemas com o título Nicanor Parra e Vinicius de Moraes. O trabalho tradutório dos antipoemas é de autoria de Nejar, enquanto que a tradução ao espanhol da obra de Vinicius de Moraes é de autoria de Maximino Fernández. A publicação é bilíngue e apresenta todos os poemas, antipoemas e paratextos em português e espanhol. Na seleção de Nejar constam dois dos mais importantes antipoemas de Parra: Solilóquio del individuo e El hombre imaginário. Carlos Nejar faz a introdução aos antipoemas apresentando Parra de forma breve e poética:

\footnotetext{
Ora lacônico e absurdo, ora concentradamente mordaz, ora fraturando o sentido para alcançar outro maior, ora na enumeração que se desvaira para configurar o revés das coisas, ora um surrealismo que se fragmenta atiçado pela própria lucidez, ora com humor desavisado, ora quebrando o protocolo e o pescoço da eloquência, através da paradoxal digressão e o antilirismo. Kafkiano no espantoso; poundiano no uso de dialogismo; de Michaux, fica-lhe o humor negro; de Vallejo certa erupção sintática; de Becket, o tom satírico. É antipomposo, e, proverbialmente alegórico, teatral, nunca deixando de ser ele mesmo, com sua máscara de um Chile ancestral, com rosto de efígie asteca (NEJAR, 2009, p. 4).
}

A seleção dos antipoemas traduzidos por Carlos Nejar aponta para um conhecimento da antipoesia e do antipoeta. O tradutor não só traduz, mas em sua seleção se estabelece uma representação do antipoético, algo que se evidencia a cada verso traduzido. Um dos antipoemas de Parra mais apreciados e lidos no Chile é o antipoema El hombre imaginário, publicado em 1985. A seguir, transcrevo o poema de Parra, juntamente com a tradução de Nejar, com o objetivo de destacar algumas escolhas do tradutor. 
El hombre imaginário

Nicanor Parra

1 El hombre imaginário

2 vive en una mansión imaginaria 3 rodeada de árboles imaginarios

4 a la orilla de un río imaginário

5 De los muros que son imaginarios 6 penden antiguos cuadros imaginarios 7 irreparables grietas imaginarias 8 que representan hechos imaginarios 9 ocurridos en mundos imaginarios 10 en lugares y tiempos imaginarios

11 Todas las tardes tardes imaginarias 12 sube las escaleras imaginarias 13 y se asoma al balcón imaginario 14 a mirar el paisaje imaginario 15 que consiste en un valle imaginario 16 circundado de cerros imaginários

17 Sombras imaginarias

18 vienen por el camino imaginario 19 entonando canciones imaginarias 20 a la muerte del sol imaginário

$21 \mathrm{Y}$ en las noches de luna imaginaria 22 sueña con la mujer imaginaria 23 que le brindó su amor imaginario 24 vuelve a sentir ese mismo dolor 25 ese mismo placer imaginario 26 y vuelve a palpitar 27 el corazón del hombre imaginário

\section{O homem imaginário}

Tradução de Carlos Nejar

O homem imaginário

vive numa mansão imaginária rodeada de árvores imaginárias à margem de um rio

Dos muros que são imaginários pendem antigos quadros imaginários irreparáveis gretas imaginárias que representam fatos imaginários ocorridos em mundos imaginários em lugares e tempos imaginários

Todas as tardes tardes imaginárias sobe as escadas imaginárias e assoma à sacada imaginária a olhar a paisagem imaginária que consiste num vale imaginário circundado de montes imaginários

Sombras imaginárias descem pelo caminho imaginário entoando canções imaginárias à morte do sol imaginário

E nas noites de lua imaginária sonha com a mulher imaginária que lhe brindou seu amor imaginário volta a sentir essa mesma dor esse mesmo prazer imaginário e torna a palpitar o coração do homem imaginário

A tradução de Carlos Nejar se debruça à tarefa de trazer a escritura de Nicanor Parra para um texto no idioma português. Na publicação dessa tradução Nejar dispõe juntamente com os antipoemas traduzidos um paratexto introdutório aos antipoemas. Temos, assim, uma reflexão crítica da antipoesia disponível ao leitor dessa tradução. No quadro comparativo acima, 
vemos que o antipoema $\mathrm{El}$ hombre imaginário, no que se refere à estética, mantém o mesmo aspecto visual ao ser traduzido. Podemos também ver nestes versos uma característica importante da antipoesia: o ritmo. Apesar de não termos a presença da rima, ou de uma métrica tradicional, a repetição das palavras imaginário, imaginárias, imaginários remete-nos a anáfora, que é uma figura de linguagem bastante constante na construção antipoética. A anáfora é um elemento de destaque para Maria Nieves Alonso, que no seu artigo El espejo y la máscara de la antipoesía destaca também o anaforismo na antipoesia como um todo, e afirma que a antipoesia não só estabelece dialogismo com textos histórico culturais, mas que também ocorre na antipoesia a autocitação, autorreferências e se relacionam poemas e antipoemas de Parra. Desta forma, a anáfora que percebemos ao analisar os versos de El hombre imaginário é um elemento constante também no projeto de escritura antipoético (ALONSO, 1978, s. p.). No verso (23): "que le brindó su amor imaginario", a escolha do tradutor foi manter a palavra "brindou". Uma outra possibilidade poderia ser substituir por "entregou", mas os antipoemas tem um ritmo, que deve ser observado ao momento de realizar a tradução. Neste verso, podemos encontrar o ritmo na sonoridade das letras "b" y "d". Para Meschonnic, a oralidade é um fazer, um funcionamento, e "a oralidade, enquanto marca característica de uma escrita, realizada na sua plenitude somente pela escrita, é o jogo da poética do traduzir"(MESCHONNIC, 2010, p. 36-37).

Ao analisar o verso (18) "vienen por el camino imaginario", detemos-nos na palavra vienen. Neste verso o tradutor opta por "descem", e não vêm. Assim a tradução ao português mantém a sonoridade do verso, importante especialmente neste antipoema. Ao traduzir ocorre a troca do verbo vir por descer, mas se mantém o ritmo do verso. No Dicionário da Real Academia Española, destaca-se um dos significados de venir: "Dicho de una persona o de una cosa: Llegar a donde está quien habla”. Modifica-se o verbo, mas a imagem das (18) sombras imaginárias aproximando-se é mantida. Na última estrofe, no verso 26 , temos o verbo volver flexionado: vuelve, que no Dicionário da Real Academia Espanhola tem como um dos seus significados "dar vuelta o vueltas a algo"; este verbo é traduzido de forma diferente em cada verso: "vuelve a sentir ese mismo dolor" para: "volta a sentir essa mesma dor" e " y vuelve a palpitar" para: “e torna a palpitar" (NEJAR, 2009, p. 95). 
Essa diferença não causa necessariamente estranheza, e se mantém a quantidade de sílabas. Ao mesmo tempo, a palavra "torna" atende a um dos significados deste verbo no espanhol: dar volta. Notamos uma tradução que está debruçada na construção poética dos versos e atenta ao seu ritmo. Neste verso o tradutor ganha certa evidência e intervem no antipoema. Para Carlos Nejar:

[...] o antipoema abriga a poesia ao avesso, poesia integralmente, sem rasuras, caminhando contra a maré das leis canônicas de uma criação estética bem comportada, em geral modulando a técnica do ritmo, sem o estuário das rimas (o que não quer dizer que não as use, episodicamente) que singularizam a lira tradicional (NEJAR, 2009, p. 4).

A tradução é uma forma de leitura e reflexão do outro, e no ato de traduzir se pode estabelecer uma aproximação com as estruturas que permeiam o antipoético. Para Antoine Berman: "Em suas regiões mais profundas, o traduzir está ligado à ética, à poesia e ao pensamento" (BERMAN, 1985, p. 34). E é somente com a reflexão e um olhar atento e sensível que podemos refletir sobre o ato de traduzir antipoemas.

Para fazer a reflexão da antipoesia podemos resgatar as duas formas tradicionais e dominantes de tradução literária apontadas por Berman, a tradução etnocêntrica e a tradução hipertextual. Etnocêntrico em Berman significa "que traz tudo à sua própria cultura, às suas normas e valores, e considera o que se encontra fora dela - o Estrangeiro - como negativo ou, no máximo, bom para ser anexado, adaptado, para aumentar a riqueza desta cultura" (BERMAN, 2007, p. 34-41). Certamente uma tradução etnocêntrica para a antipoesia nos traria muitas perdas, entre elas a mesma intertextualidade com o contexto chileno, perderíamos os versos que resgatam o folclore e os personagens chilenos. Faz parte da antipoesia também a utilização da variação chilena da língua, nesse caso, o tradutor terá que analisar a cada antipoema como proceder para trazer ao português características da fala coloquial chilena. Um exemplo em outras obras, seria o cartão postal abaixo, publicado pela galeria de arte Época, contido na obra Chistes Parra desorientar a la polícia poesía (1983): 


\section{Figura 1 - Chistes}

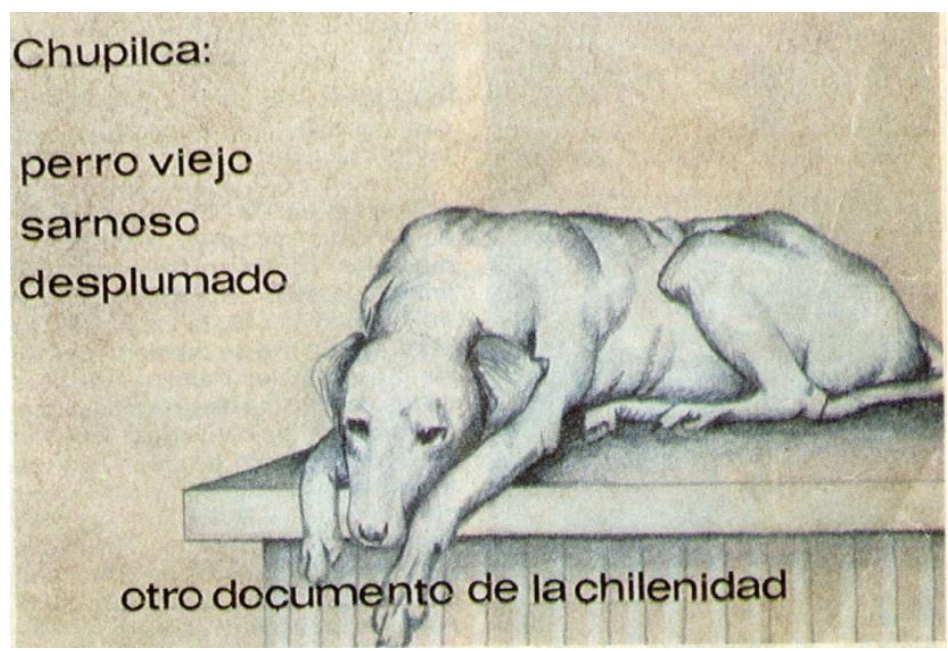

Fonte: PARRA, Nicanor. Tarjeta postal de Chistes Parra desorientar a la policía la poesia. São Paulo, 1983.

Nesta postal temos o quiltro, cão vira-lata, que é um personagem conhecido nas praças e parques chilenos. O antipoema neste caso, é um chiste, publicado em forma de postal. Chupilca é uma palavra de origem quechua, que remete a uma bebida popular chilena, feita de farinha tostada e da chicha (fermentação da uva) de vinho. O quiltro é um termo incorporado na linguagem chilena. E este seria mais um aspecto da antipoesia, o seu idioma espanhol chileno, que é uma linguagem que recebe influência dos idiomas dos povos originários.

No antipoema La Trampa (1954) traduzido por Nejar, podemos observar uma tradução que se afasta do etnocêntrico e que introduz uma palavra que remete a realidade e a um idioma traduzido. O leitor se vê em contato com nomes de lugares latino-americanos. A menção de um local típico chileno: "fuente de soda", se refere a um lugar comum nos bairros centrais da capital chilena, onde se almoça, se compram lanches e bebidas. Fuente de Soda ${ }^{5}$ é traduzida para o português como: "fonte de soda". Essa tradução, que poderia ser considerada literal ou estrangeirizante, leva o leitor até um local latino-americano, que no Brasil poderíamos chamar

\footnotetext{
5 Sua origem pode estar associada a "Sodas Fountain" bares da década de 50, é considerado um californismo. wiktionary.org: "bar americano".
} 
de lanchonete ou bar. Abaixo versos do poema La Trampa, publicado em Poemas y Antipoemas (1954):

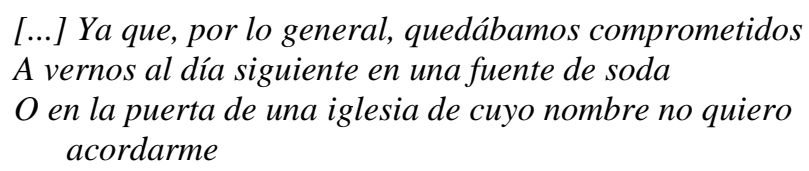

(NEJAR, 1954 [2009], p. 134)

Percebemos nesse antipoema a presença marcante de duas culturas, a chilena, aqui sendo representada no local chileno "fuente de soda", e no último verso, alusão à obra ícone do idioma espanhol: Don Quixote; Parra remete a obra espanhola e encerra um dos versos com uma das frases mais conhecidas da obra de Cervantes. A intertextualidade com a realidade chilena se conecta com um mito, o antipoeta faz menção à literatura hispana e sua erudição se deixa notar a cada verso.

\footnotetext{
"de cuyo nombre no quiero acordarme"
}

Cabe destacar o cuidado de Carlos Nejar com a forma de todos os antipoemas. O tradutor respeita os espaços e mantém o formato estético das publicações em espanhol. No poema "Autoretrato", em seus últimos versos observamos a introdução de uma expressão idiomática: [...] Y qué les sugieren estos zapatos de cura
que envejecieron sin arte ni parte.

(PARRA, 1954 [2006], p. 25)

\section{[...] E que lhes sugerem estes sapatos de pároco que envelheceram sem arte nem parte.}

(Tradução de Nejar, 2009)

"Envelhecer sem arte nem parte", pode não ser uma expressão amplamente conhecida no português brasileiro. "No tener arte ni parte" tem como um dos seus significados no espanhol, a falta de possibilidade de intervenção em determinado assunto. Ou seja, envelhecer 
sem o poder de mudar tal envelhecimento. Desta forma, ocorre a introdução de uma expressão à língua de chegada. A tradução aqui traduz as palavras e deixa com o leitor a tarefa de interpretar esse verso.

\section{Considerações finais}

Em 2004, a jornalista María Teresa Cárdenas pergunta a Parra: "E se da fala comum se trata: quais são as possibilidades da tradução? Parra é categórico: "A poesia não se pode traduzir. Essa é a resposta. Shakeaspeare, que já estava em uma poesia da fala, não se pode traduzir ao castelhano". Se deve então, reescrevê-lo" (PARRA, 2006, p. 53) ${ }^{6}$.

Ao analisar os dois projetos de tradução aqui citados, percebemos a riqueza de possibilidades da antipoesia ao momento de traduzir, e junto com essa característica estão também suas muitas dificuldades. Os dois projetos são vitais e importantes, são precursores na tradução da antipoesia no Brasil. Mais que qualquer receita prescritiva, na antipoesia o tradutor terá que se propor a leitura do antipoético de forma ampla, e com cuidado a cada verso, em cada detalhe descobrir suas camadas e suas intertextualidades. Talvez as maiores dificuldades estejam nas palavras e versos que aparentam ser de simples tradução.

Estamos, sim, em um contexto de ruptura, mas estamos em um texto que agrega o poético. Os antipoemas, quando no formato de verso livre, constituem-se com estética, períodos e ritmos que pedem ser observados. Se retomamos Berman, a tradução dos antipoemas vai na direção do albergue do longíquo, requer um trabalho tradutório voltado para conhecer e receber o outro, neste caso a outra, a antipoesia.

\section{Referências}

ALONSO, Maria Nieves. El espejo y la máscara de la antipoesia: Revista Atenea, Concepción, separata $\mathrm{n}^{\circ} 438,1978$.

\footnotetext{
6 "Y si de habla común se trata, ¿cuáles son las posibilidades de la traducción? Parra es categórico: «La poesía no se puede traducir. Ésa es la respuesta. Shakeaspeare, que ya estaba en una poesía del habla. no se puede traducir al castellano» Lo que hay que hacer entonces es reescribirlo" (PARRA, 2006, p. 53).
} 
BERMAN, Antoine. A tradução e a letra ou o Albergue do Longínquo. Rio de Janeiro: 7 Letras; PGET, 2007.

BERMAN, Antoine. Prova do estrangeiro: cultura e tradição na Alemanha romântica. Bauru: EDUSC, 2002.

BINSS, Niall. ¿Qué hay en un nombre? Poemas y antipoemas u. Oxford 1950. Taller de Letras, Universidad Complutense, n. 48, 2011. Disponível em:

<http://www7.uc.cl/letras/html/6_publicaciones/pdf_revistas/taller/t148/10_Doc_Binns_TL48.pdf>. Acesso em: 10 de outubro de 2015.

BOLAÑO, Roberto. El exilio y la Literatura. Discurso en Viena de Roberto Bolaño. Venezuela: Revista Ateneo, Madrid, n. 15, p. 42-44, 2001.

JOFRE, Manuel. Poeta Nicanor entrevista a Parra antipoeta. Santiago: Universidad de Chile, 2000. Disponível em: <www.nicanorparra.uchile.cl/entrevistas/poetanicanor.html>. Acesso em: 10 mar. 2015.

MESCHONNIC, Henri. Poética do traduzir. São Paulo: Perspectiva, 2010.

MORALES, Leonidas. Nicanor Parra: El proyecto antipoético: Santiado do Chile. Anales de literatura chilena, Chile, v. 13, n. 17, p. 147-167, jun. 2012.

MOREU, Salvador G. Antipoesía e ironía: una introducción. 2008. Disponível em: $<$ https://pendientedemigracion.ucm.es/info/especulo/numero38/antipoes.html $>$. Acesso em: $12 \mathrm{de}$ outubro de 2015.

NEJAR, Carlos. Nicanor Parra, los antipoemas. In: NICANOR Parra e Vinicius de Moraes. Rio de Janeiro: Academia Brasileira de Letras. 2009.

NETO, Juvenal, (Ed.). Quatro poetas latino-americanos por Juvenal Neto. Pirâmide, Revista de Vanguarda, Cultura e Arte, São Paulo, v. 1, n. 1, p. 67-92, 1981.

PARRA, Nicanor. Obras Completas \& algo +I. Barcelona: Galáxia Gutemberg, 2006.

PEÑA, Carlos. Presentación Antiprosa. 2015. Disponível em: < http://ediciones.udp.cl/antiprosanicanor-parra/>. Acesso em: 20 mar. 2015.

RAMA, Angel. La ciudad Letrada. Montevidéu: Andes, 1998.

SCHOPF, Federico. Del Vanguardismo a la antipoesía. Introducción a la antipoesía de Nicanor Parra. Prólogo de Poemas y Antipoemas de Nicanor Parra. Santiago do Chile: Nacimento. 1984.

Mary Anne Warken S. Sobottka - Universidade Federal de Santa Catarina - UFSC | Florianópolis | Santa Catarina. Contato: warkenespanholufsc@gmail.com 